\title{
Gross Anatomic and Scanning Electron Microscopic Studies on the Mandibular Condyles of the Human Cadavers
}

\author{
By \\ M. Hamit ÇELIK*, Mustafa F. SARGON** and H. Hamdi ÇELIK*** \\ *Assistant Professor in Department of Periodontology, Hacettepe University, Faculty of Dentistry, Ankara, \\ 06100 Turkey \\ **Assistant Professor in Department of Anatomy, Hacettepe University, Faculty of Medicine, Ankara, 06100 Turkey \\ ***Associate Professor in Department of Anatomy, Hacettepe University, Faculty of Medicine, Ankara, 06100 Turkey
}

- Received for Publication, April 1, 1998 -

Key Words: Mandibular condyle, Anatomy, Scanning electron microscopy, Human cadavers

\begin{abstract}
Summary: The mandibular condyles of 30 cadavers were examined bilaterally. The greatest medial-lateral lengths and greatest anterior-posterior widths of these condyles were measured with a millimeter caliper. The mean size of the greatest medial-lateral length of the superior surface of the condyle between males and females was significantly different. On the other hand, the mean size of the greatest anterior-posterior width of this surface between males and females was not significant. In gross anatomic examination, 28 of the 60 condyles (46.6\%) had a convex articulating surface without having any surface irregularities. However, 32 of the 60 condyles (53.4\%) demonstrated irregular articular surfaces with characteristic flattening and eburnation. Half of these surface irregularities were found in the lateral part and a few of them were located in the medial part and superior surface of the condyles. Short, irregular undulations, surface depressions and sharply demarcated microcraters were observed in the SEM examination of mandibular condyles having macroscopic abnormalities. These osseous abnormalities were present in the mandibular condyles of people, who were over the age of 50 years and they were very prominent especially in the ones who were completely edentulous. Therefore remodeling of the articular surface might occur in response to alteration of functional forces within the joints of these aged individuals.
\end{abstract}

Functional disturbances in the masticatory system are very common and about half of the adult western population have the symptoms of them. ${ }^{2)}$ The etiology of these disturbances is multifactorial and the frequency of them increases with age. ${ }^{5,7)}$ Anterior disc displacement, ${ }^{14)}$ loss of molar support, micro-trauma ${ }^{10,12)}$ and altered loading patterns due to bruxism or other oral parafunctions are the factors which are very important in the formation of temporomandibular osteoarthrosis and osteoarthritis. $^{8)}$ Additionally, the frequency of these pathologies increases with age. ${ }^{6,7)}$

In this study, we examined the mandibular condyles of cadavers and noted the changes in size and distribution of irregular macroscopic and ultrastructural features. Secondly, the surface of the condyles are examined ultrastructurally by using scanning electron microscope and the results are noted.

\section{Materials and Methods}

The mandibular condyles of 30 white Turkish human cadavers were examined bilaterally. Eighteen of the specimens were male (34-72 years of age) and 12 of them were female (28-69 years of age). Nineteen of the specimens were completely edentulous, and eleven of them were partially edentulous, with a range of 2 to 11 teeth remaining in the mandible (Table 1).

Dissection technique: The temporomandibular joints of the cadavers were dissected by an incision extending from the tragus along the posterior border of the ramus to the mandibular angle and releasing the stylomandibular ligament attachment. A second incision was made parallel to the base of the mandible releasing the mylohyoid muscle, anterior belly of the digastric muscle, genioglossus muscle, geniohyoid muscle and associated structures. In- 
Table 1. Summary of the linear morphologic data for 60 mandibular condyles demonstrating normal gross anatomic appearance and osseous abnormalities (Teeth: Number of teeth remaining, MLL: Greatest medial-lateral length in millimeters, APW: Greatest anterior-posterior width in millimeters, Abnor: Macroscopic osseous abnormalities).

\begin{tabular}{|c|c|c|c|c|c|c|c|c|c|c|}
\hline No & $\begin{array}{l}\text { Age } \\
\text { Male }\end{array}$ & $\begin{array}{l}\text { Teeth } \\
\text { Male }\end{array}$ & $\begin{array}{l}\text { MLL } \\
\text { Male }\end{array}$ & $\begin{array}{l}\text { APW } \\
\text { Male }\end{array}$ & $\begin{array}{l}\text { Abnor } \\
\text { Male }\end{array}$ & $\begin{array}{c}\text { Age } \\
\text { Female }\end{array}$ & $\begin{array}{c}\text { Teeth } \\
\text { Female }\end{array}$ & $\begin{array}{c}\text { MLL } \\
\text { Female }\end{array}$ & $\begin{array}{c}\text { APW } \\
\text { Female }\end{array}$ & $\begin{array}{l}\text { Abnor } \\
\text { Female }\end{array}$ \\
\hline 1 & 34 & 11 & 16.8 & 6.9 & - & 28 & 10 & 15.9 & 6.5 & - \\
\hline 2 & 34 & 11 & 16.9 & 7.0 & - & 28 & 10 & 16.2 & 6.8 & - \\
\hline 3 & 36 & 9 & 17.3 & 7.2 & - & 33 & 8 & 17.3 & 6.9 & - \\
\hline 4 & 36 & 9 & 18.0 & 7.7 & - & 33 & 8 & 17.7 & 7.3 & - \\
\hline 5 & 39 & 9 & 19.8 & 7.8 & - & 42 & 5 & 18.9 & 8.1 & - \\
\hline 6 & 39 & 9 & 20.1 & 8.2 & - & 42 & 5 & 18.9 & 8.5 & - \\
\hline 7 & 41 & 8 & 21.2 & 8.3 & - & 46 & 2 & 20.8 & 8.7 & - \\
\hline 8 & 41 & 8 & 21.2 & 9.0 & - & 46 & 2 & 21.3 & 9.3 & - \\
\hline 9 & 46 & 7 & 22.1 & 9.1 & - & 51 & - & 21.9 & 9.9 & + \\
\hline 10 & 46 & 7 & 22.3 & 9.7 & - & 51 & - & 22.5 & 10.3 & + \\
\hline 11 & 47 & 5 & 22.4 & 9.9 & - & 53 & - & 23.0 & 11.8 & + \\
\hline 12 & 47 & 5 & 22.8 & 10.1 & - & 53 & - & 23.6 & 12.6 & + \\
\hline 13 & 50 & 3 & 16.9 & 7.1 & - & 54 & - & 15.9 & 6.6 & + \\
\hline 14 & 50 & 3 & 17.1 & 7.1 & - & 54 & - & 16.1 & 6.9 & + \\
\hline 15 & 52 & 0 & 17.3 & 7.4 & + & 57 & - & 16.8 & 7.0 & + \\
\hline 16 & 52 & 0 & 18.8 & 7.8 & + & 57 & - & 17.8 & 7.3 & + \\
\hline 17 & 55 & 0 & 19.2 & 8.2 & + & 60 & - & 18.6 & 7.9 & + \\
\hline 18 & 55 & 0 & 19.7 & 8.4 & + & 60 & - & 19.1 & 8.0 & + \\
\hline 19 & 58 & 0 & 20.2 & 9.0 & + & 63 & - & 19.9 & 8.0 & + \\
\hline 20 & 58 & 0 & 20.8 & 9.8 & + & 63 & - & 21.0 & 8.9 & + \\
\hline 21 & 59 & 0 & 21.7 & 10.1 & + & 64 & - & 21.7 & 9.8 & + \\
\hline 22 & 59 & 0 & 22.1 & 10.6 & + & 64 & - & 21.8 & 10.5 & + \\
\hline 23 & 61 & 0 & 22.4 & 11.0 & + & 69 & - & 22.9 & 12.0 & + \\
\hline 24 & 61 & 0 & 22.8 & 11.2 & + & 69 & - & 23.5 & 12.2 & + \\
\hline 25 & 61 & 0 & 22.9 & 11.5 & + & & & & & \\
\hline 26 & 61 & 0 & 23.1 & 12.0 & + & & & & & \\
\hline 27 & 64 & 0 & 23.3 & 12.0 & + & & & & & \\
\hline 28 & 64 & 0 & 24.0 & 12.3 & + & & & & & \\
\hline 29 & 65 & 0 & 24.1 & $12.7^{\circ}$ & + & & & & & \\
\hline 30 & 65 & 0 & 24.3 & 12.9 & + & & & & & \\
\hline 31 & 68 & 0 & 22.9 & 11.5 & + & & & & & \\
\hline 32 & 68 & 0 & 23.1 & 11.8 & + & & & & & \\
\hline 33 & 70 & 0 & 23.2 & 12.1 & + & & & & & \\
\hline 34 & 70 & 0 & 23.7 & 12.4 & + & & & & & \\
\hline 35 & 72 & 0 & 24.0 & 12.6 & + & & & & & \\
\hline 36 & 72 & 0 & 24.1 & 12.8 & + & & & & & \\
\hline
\end{tabular}

cisions contiguous to the internal aspect of the ramus releasing the sphenomandibular ligament and the pterygoid and temporalis muscles were made. The zygomatic arch was exposed and removed to increase access to the anterior superior portion of the joint. The disk and the condyle were subsequently freed from the temporal fossa, with the disk remaining attached to the condylar head.

The disk was then released from the condyle and fixed samples taken from the cadavers were put into $5 \%$ sulphuric acid solution at room temperature for 6 hours, in order to remove the fixed protein in the synovia. Then, the surface irregularities and abnormalities in the osseous contour of the condyle were noted. The greatest medial-lateral length and greatest anterior-posterior width dimensions of the superior surface of the condyles were measured with a millimeter caliper. Secondly, the superior surface of mandibular condyles were examined by scanning electron microscopy and ultrastructural changes were detected.

SEM Examination: After the gross anatomic examination, these fixed samples taken from the cadavers were dehydrated in increasing concentrations of acetone and critical point dried, mounted on metal stubs with conductive silver paint and then sputtered with a $100 \mathrm{~A}^{0}$ thick layer of gold in a BIO-RAD sputter apparatus. The condyles were examined with a Jeol scanning electron microscope (SEM ASID-10) at an acceleration voltage of 80 KV. 


\section{Results}

Gross Anatomic Examination: The mean size of the greatest medial-lateral length of the superior surface of the condyle between males $(21.18 \pm 2.45$ $\mathrm{mm})$ and females $(19.71 \pm 2.60 \mathrm{~mm})$ was significantly different $(P<0.05)$. On the other hand, the mean size of the greatest anterior-posterior width of this surface between males $(9.86 \pm 2.02 \mathrm{~mm})$ and females $(8.82 \pm 1.92 \mathrm{~mm})$ was not significant.

Twenty eight of the 60 condyles $(46.6 \%)$ had a convex articulating surface without having any surface irregularities (Fig. 1). Thirty two of the 60 condyles $(53.4 \%)$ demonstrated osseous abnormalities consisting of irregular articular surfaces with characteristic flattening and eburnation of the condyle. Half of these surface irregularities were found in the lateral part and a few of them were located in the medial part and superior surface of the condyle (Fig. 2).

Scanning electron microscopic examination: In the SEM examination of 28 condyles which appeared normal in gross anatomic examination, the surfaces were smooth and there were no irregular undulations (Fig. 3). Short, irregular undulations about 7-40 $\mu \mathrm{m}$ apart (Fig. 4) and surface depressions about $1-5 \mu \mathrm{m}$ in diameter (Fig. 5) were observed in the condyles having osseous abnormalities. Superimposed on these irregularities were a number of sharply demarcated microcraters about $0.5-2.2 \mu \mathrm{m}$ in diameter (Fig. 4).

\section{Discussion}

Macroscopic examination of the surface structure of temporomandibular joint have been studied by many authors. ${ }^{3,13,14,17)}$ The shape of the mandibular condyle is convex normally and its mediallateral length is approximately twice that of the anterior-posterior width. ${ }^{9,15-17)}$ The sizes of the condyles obtained in this study are in agreement with earlier presented results, but the shape of the examined condyles were in disagreement with the other studies found in the literature. Some authors reported that $58 \%$ of the condyles were found to be convex, but in our study this ratio was $46.6 \% .{ }^{17)}$ We observed that the condyles of people, who were over the age of 50 years had demonstrated osseous abnormalities and therefore, this difference might be the result of the higher number of aged individuals in our study group. The localization of the surface irregularities were in good agreement with earlier presented results. ${ }^{11,12)}$ In the study of Ebner et $a .^{4)}$ the found sizes of the medial-lateral length of female condyles were significantly smaller than those of male condyles, whereas greatest anteriorposterior width of the condyles did not show any marked difference between these two sexes in their study. However in our study, greatest mediallateral length and greatest anterior-posterior width of the condyles were found to be smaller in females than in males. The mean size of the greatest mediallateral length of the superior surface of the condyle between males and females was significantly different, but the mean size of the greatest anteriorposterior width of this surface between males and females was not significant.

Short, irregular undulations, surface depressions and sharply demarcated microcraters observed in the SEM examination were present in the mandibular condyles of people, who were over the age of 50 years. The results of this study indicate that osseous abnormalities observed in the gross anatomic and SEM examination of the condyles are directly related with aging and these abnormalities are very prominent especially in the ones, who are completely edentulous.

As a result, remodeling of the articular surface may occur in response to alteration of functional forces within the joints of these aged individuals.

\section{References}

1) Akerman S, Rohlin $M$ and Kopp S. Bilateral degenerative changes and deviation in form of temporomandibular joints. An autopsy study of elderly individuals. Acta Odontol Scand 1984; 42:205-214.

2) Carlsson G. Epidemiological studies of signs and symptoms of temporomandibular joint-pain-dysfunction. A literature review. Australian Prosthod Soc Bulletin 1984; 14:7-12.

3) Delfino JJ and Eppley BL. Radiographic and surgical evaluation of internal derangements of the temporomandibular joint. J Oral Maxillofac Surg 1986; 44:260-267.

4) Ebner KA, Otis LL, Zakhary $R$ and Danforth RA. Axial temporomandibular joint morphology: A correlative study of radiographic and gross anatomic findings. Oral Surg Oral Med Oral Pathol 1990: 69:247-252.

5) Ericson $S$ and Lundberg $M$. Structural changes in the finger, wrist and temporomandibular joints. A comparative radiological study. Acta Odontol Scand 1968; 26:111-126.

6) Heloe B and Heloe LA. Characteristics of a group of patients with temporomandibular joint disorders. Community Dent Oral Epidemiol 1975; 3:27-29.

7) Madsen G. Normal variations in anatomy, condylar movements and arthrosis frequency of the temporomandibular joints. Acta Radiol 1996; 4:273-288.

8) Mejersjö C. Therapeutic and prognostic considerations in TMJ osteoarthrosis. A literature review and a long-term study in 11 subjects. J Craniomand Pract 1987; 5:69-78.

9) Moffett $B$. The morphogenesis of the temporomandibular joint. Am J Orthod 1966; 52:410-415.

10) Mongini F. Remodelling of the mandibular condyle in the adult and its relationship to the condition of the dental arches. Acta Anat 1972; 82:437-453.

11) Nannmark U, Sennerby $L$ and Haraldson T. Macroscopic, microscopic and radiologic assessment of the condylar part 
of the TMJ in elderly subjects. An autopsy study. Swed Dent J 1990; 14:163-169.

12) Öberg T, Carlsson GE and Fajers CM. The temporomandibular joint. A morphologic study on a human autopsy material. Acta Odontol Scand 1971; 29:349-384.

13) Richards LC. Temporomandibular joint morphology in two Australian aboriginal populations. J Dent Res 1987; 66:1602-1607.

14) Westesson PL and Rohlin M. Internal derangement related to osteoarthritis in temporomandibular joint autopsy specimens. Oral Surg Oral Med Oral Pathol 1984; 57:17-
22.

15) Whittaker DK, Davies G and Brown M. Tooth loss attrition and temporomandibular joint changes in a RomanoBritish population. J Oral Rehabil 1985; 12:407-419.

16) Worth HM. The role of radiological interpretation in disease of the temporomandibular joint. Oral Sci Rev 1974; 6:3-51.

17) Yale SH, Allison BD and Hauptfuehrer JD. An epidemiological assessment of mandibular condyle morphology. Oral Surg Oral Med Oral Pathol 1966; 21:169-1. 
Plate I

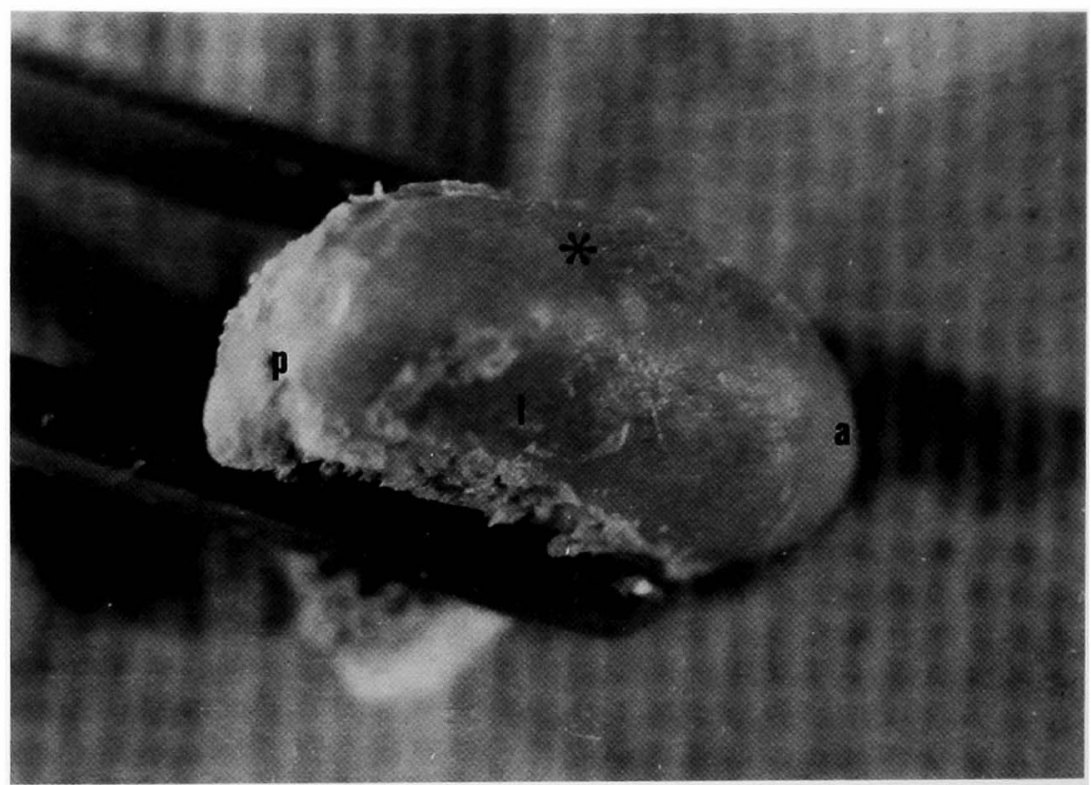

\section{Explanation of Figures}

\section{Plate I}

Fig. 1. Photography of the superior surface of a condyle demonstrating a convex articulating surface without any surface irregularities (* Superior surface, a: Anterior part, p: Posterior part, l: Lateral part of the condyle). 
Plate II

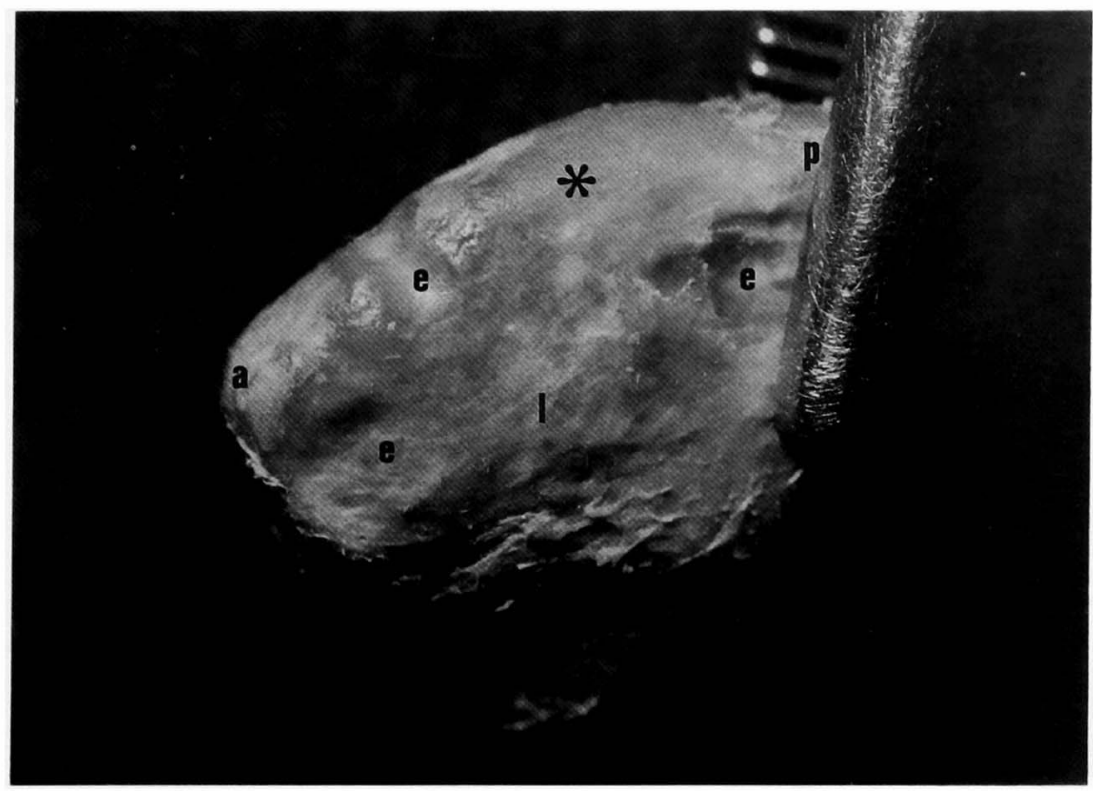

\section{Plate II}

Fig. 2. Photography of the superior surface of a condyle demonstrating osseous abnormalities. Surface erosions (e) in the lateral part and superior surface of the condyle are seen (* Superior surface, a: Anterior part, p: Posterior part, l: Lateral part of the condyle). 
Plate III

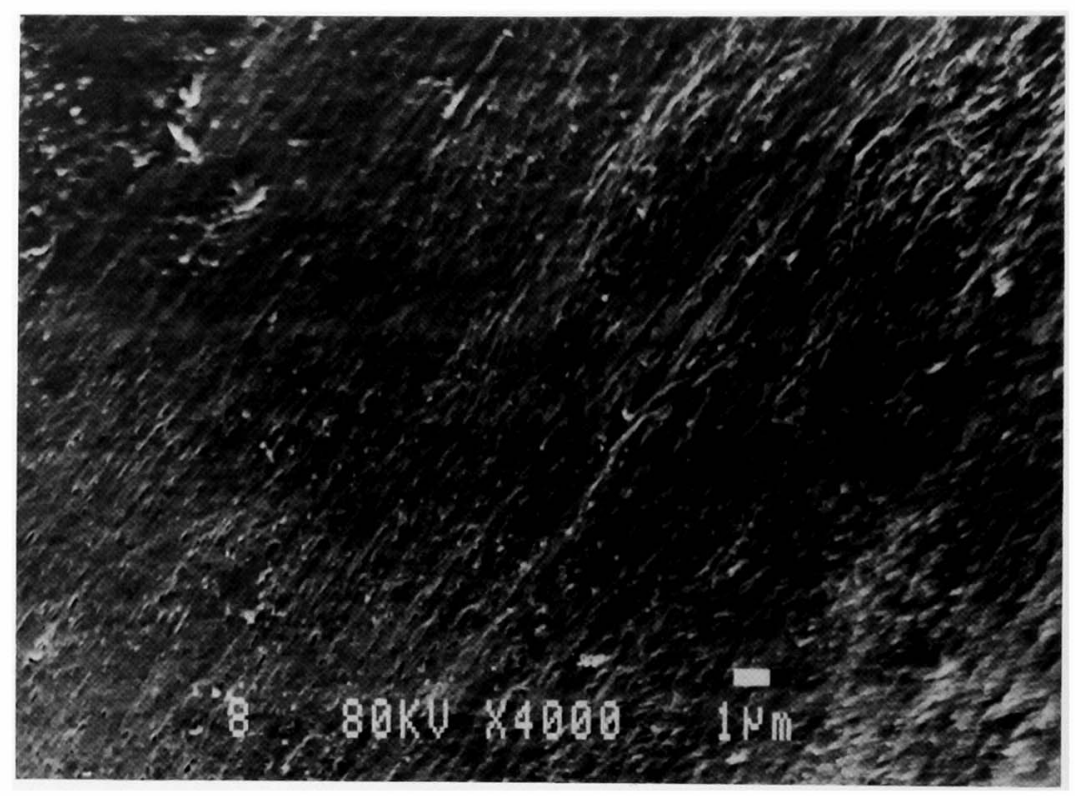

\section{Plate III}

Fig. 3. Scanning electron micrograph of a mandibular condyle having a smooth surface without any undulations and depressions (Bar represents $1 \mu \mathrm{m}$ ). 
Plate IV

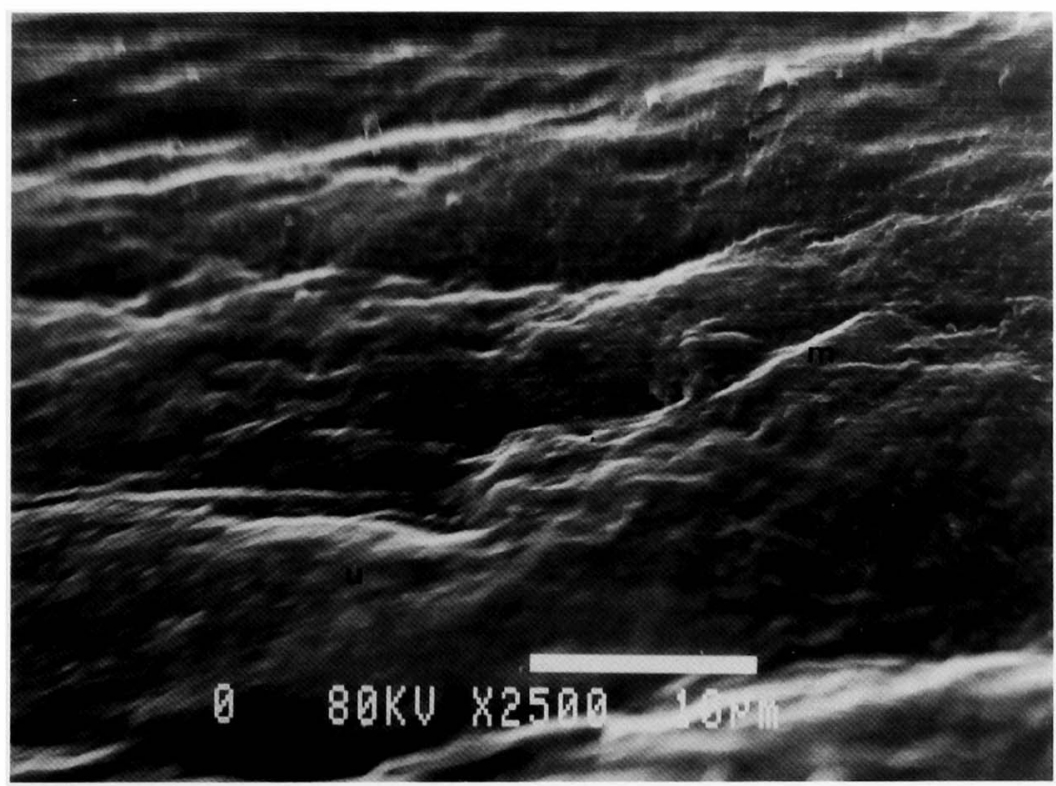

\section{Plate IV}

Fig. 4. Scanning electron micrography of a mandibular condyle demonstrating short irregular undulations (u) and microcraters (m) (Bar represents $10 \mu \mathrm{m}$ ). 


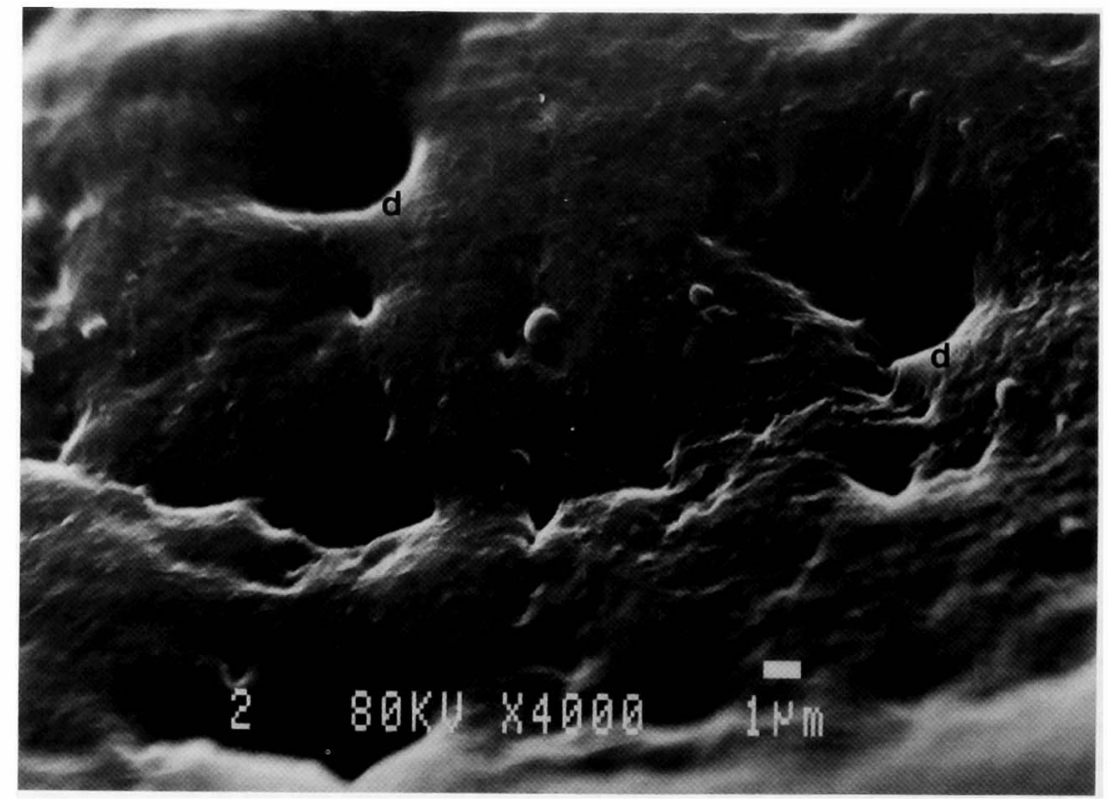

Plate V

Fig. 5. Scanning electron micrography of a mandibular condyle showing surface depressions (d) (Bar represents $1 \mu \mathrm{m}$ ). 